\title{
National Science Foundation taking a bipolar perspective
}

\section{Washington}

THE National Science Foundation (NSF) is formulating plans for a new initiative for polar studies. Called Arctic System Science (ARCSS), the new programme, planned to start in 1989 , will take a multidisciplinary approach to Arctic studies, in much the same way as the International Geosphere/Biosphere Program will examine a variety of Earth systems in studying global change.

The NSF has given a lot of attention to the Arctic in recent months. The Arctic Research and Policy Act of 1984 created the Arctic Research Commission and the Interagency Research Policy Committee, both chaired by NSF. The committee has now produced the 5-year US Arctic Research Plan, signed by President Reagan and soon to be transmitted to Congress.

A special task committee of the National Science Board has also just completed a report of NSF's role in the polar regions. Chaired by Board member Rita Colwell, the report recommends that science rather than available logistics - should dictate Arctic programmes. Because the poles are difficult environments to work in, it is important that research plans accommodate as many intersecting inter- ests as possible. The Colwell report urges NSF to taking a leading role in the development of polar activities among interested US agencies.

The Arctic is looked on as a sensitive indicator of changes in the global climate - in fact it may not only reflect global environmental changes, it may drive them. Melting ice from the poles may release methane, another greenhouse gas, and that could increase global warming in a positive feedback system.

The ARCSS initiative is intended to start a number of projects that will study the forces controlling the polar environment. One project, Arctic land-air interactions, will attempt to study how changes in Arctic ecosystems are driven by the global climate. Another, high-latitude oceanic and atmospheric processes, will examine how energy exchanges alter circulation patterns in the Arctic Ocean

ARCSS is currently under internal review at NSF as the agency prepares for negotiations with the White House Office of Management and Budget over its 1989 budget. But with the often repeated intention of doubling the NSF budget over the next five years, new initiatives like ARCSS appear to have a good chance of being adopted.
Joseph Palca

\section{Aurora borealis pair for Soviet launcher?}

\section{Garching, West Germany}

A group of Western European space scientists are turning to the Soviet Union for a rocket to launch their next satellite experiment. The project, called "Turbulence", involves putting two satellites into polar orbits in 1993 in an international project to study the physics of the aurora borealis.

Sweden, West Germany and Great Britain are expected to share the estimated DM100 million cost of the two satellites. The Soviets and others will be invited to contribute telemetry equipment and make measurements of their own using the satellites. Gerhard Haerendel of the MaxPlanck Institute for Extraterrestrial Physics at Garching, who is one of the inititators of the project, says that using a Soviet rocket would cut costs. An Ariane 4 rocket, built by the European Space Agency, would cost 80 million ECU (European Currency Units, 1ECU $=0.70$ ), said Haerendel, and there would be "no chance" of obtaining this money from the governments in question. The Soviet Union will provide the rocket for nothing, Haerendel said, in exchange for "data like everyone else gets" as well as the prestige of launching a Western satellite.

Soviet approval of the project is un- official as yet, but Academician Roald Sagdeev, science adviser to Mikhail Gorbachev, has "promised" Haerendel that it will go on as planned. Sagdeev, himself a plasma physicist, is director of IKI, the most influential space science institute in the Soviet Union.

Only two satellites have been launched so far to study primary aurora borealis phenomena - the S3-3 of the US Air Force and the Swedish Viking satellite. Viking, launched in 1986, has already made impressive observations of the exchange of electric current between the magnetosphere and ionosphere, currents which arise in part due to the solar wind. Japan is due to launch a satellite called EXOS-D in 1989 which will also be able to inject charged particles into the magnetosphere and detect them after they "boomerang" back to the spacecraft. Turbulence hopes to go further and fire electrons and charged particles between two spacecraft oriented along the same magnetic field line.

Researchers in the three countries involved are in the preliminary stages of applying for funding for Turbulence. Haerendel said he expects approval "not before mid-1989". Steven Dickman

\section{Soviet trio in US Congress}

\section{Washington}

IN an unusual move, three Soviet scientists travelled to Washington last week to testify before the new US House of Representatives subcommittee on international scientific cooperation. A biologist, a glaciologist and an atmospheric scientist from the Soviet Academy of Sciences brought a message to Congress stressing the urgent need for international participation in the International Geosphere/Biosphere Program (IGBP) to study global change.

IGBP was launched at a meeting of the International Council of Scientific Unions (ICSU) last year, as a way to commemorate the 25th anniversary of the International Geophysical Year programme, and to expand upon its successes. ICSU is coordinating the progamme, and the United States, the Soviet Union, Sweden, Canada, France, Japan and the People's Republic of China have agreed to join.

In July, the ICSU special committee for IGBP met in Paris, and established three working groups dedicated to global modelling, data handling and exchange, and the reconstruction of past changes in the Earth's environments. Harold Mooney, chairman of the committee representing the United States to ICSU, says planning is expected to extend until 1991 , with the programme scheduled to begin in 1992.

The US efforts in IGBP will be divided between several agencies - research programmes are under way or are being planned that will tie into programmes by the National Science Foundation (see this page), the National Aeronautics and Space Administration and the National Oceanic and Atmospheric Administration, among others.

Two of the Soviet scientists who testified at the hearing, V.M. Kotlyakov and V.A. Troitskaya, are part of the ICSU committee for IGBP. Their testimony focused on past successful smaller international science collaborations, such as the Unesco Man and the Biosphere Programme, and the possible technical and political stumbling blocks that could stand in the way of IGBP.

The Soviets spoke in English, with only occasional help from an interpreter, and language and cultural barriers were still evident. But the Soviets' message, as given by the third scientist, V.E. Sovolov, carried through. He said "survival and development of each and all is a task that can be fulfilled only by all humanity, no people and no state being able to tackle it single-handed". The Soviet Union will host a meeting on IGBP in August, 1988, to discuss data exchange. Carol Ezzell 